\title{
PRÁTICAS EDUCATIVAS E RESSIGNIFICAÇÕES DOS SABERES E FAZERES DAS BANDAS CABAÇAIS RURAIS: AÇÕES DECOLONIAIS NO CONTEXTO MUSICAL URBANO/CONTEMPORÂNEO
}

\author{
PRACTICAS EDUCATIVAS Y RESIGNIFICACIONES DEL CONOCIMIENTO Y \\ HACER DE BANDAS DE PÍFANOS: ACCIONES DESCOLONIALES EN EL \\ CONTEXTO MUSICAL URBANO/CONTEMPORÁNEO
}

\author{
EDUCATIONAL PRACTICES AND RESIGNIFICATIONS OF THE RURAL \\ CABAÇAIS BANDS: DECOLONIAL ATTITUDES IN THE URBAN/CONTEMPORARY \\ MUSICAL ENVIRONMENT
}

\author{
Elinaldo Menezes BRAGA ${ }^{1}$ \\ Marizete LUCINI ${ }^{2}$
}

RESUMO: As Bandas Cabaçais, também chamadas de Bandas de Pífanos ${ }^{3}$, são grupos musicais de tradição rural existentes no Nordeste brasileiro desde o período colonial. Hegemonicamente constituídas por homens e vinculadas ao catolicismo popular, não dispensam oportunidades para profanar e libertar a brasilidade das masmorras capitalistas que negam a pluralidade, silenciam saberes, não reconhecem práticas educativas outras e condenam ao esquecimento tudo o que rompe com os padrões impostos pelo projeto de modernidade colonialista. Na contemporaneidade, contudo, esses grupos têm recebido olhares por parte de músicos urbanos, pesquisadores e produtores culturais, cujos trabalhos têm contribuído para o surgimento de projetos que ressignificam o fazeres populares tendo as Bandas Cabaçais como fontes de saberes e modos outros de existirem. Neste trabalho de cunho qualitativo, destacamos experiências de algumas musicistas para compreendermos por quais práticas educativas elas e outros/as novos/as pifeiros/as urbanos aprendem, transmitem, aprendem e ressignificam a cultura cabaçal. A coleta dos dados se deu através de entrevistas pelo whatsapp. Esperamos que os exemplos em tela inspirem e despertem o interesse de muitos outros(as) musicistas pela arte cabaçal.

PALAVRAS-CHAVE: Educação. Banda Cabaçal. Práticas educativas. Cultura popular.

RESUMEN: Las Bandas Cabaçais, también llamadas Bandas de Pífanos, constituidas hegemónicamente por hombres, son grupos de música que existen en el Nordeste desde la época colonial. Vinculados al catolicismo popular, no prescinden oportunidades para profanar y liberar la brasileña de las mazmorras capitalistas, que, entre otras cosas, niegan la pluralidad, silencian el conocimiento, no reconocen otras prácticas educativas y condenan

${ }^{1}$ Universidade Federal de Sergipe (UFS), São Cristóvão - SE - Brasil. Doutorando no Programa de PósGraduação em Educação, Departamento de Educação. ORCID: https://orcid.org/0000-0002-8056-3430. E-mail: naldinhobraga2018@gmail.com

${ }^{2}$ Universidade Federal de Sergipe (UFS), São Cristóvão - SE - Brasil. Professora do Departamento de Educação. Doutorado em Educação (UNICAMP). ORCID: https://orcid.org/0000-0003-1532-8968. E-mail: marizetelucini@gmail.com

${ }^{3} \mathrm{O}$ pífano é uma flauta transversal rústica, feita de bambu, pvc, alumínio etc. Possui seis furos para digitação e um para o sopro. O músico que a executa é chamado de pifeiro.

RIAEE - Revista Ibero-Americana de Estudos em Educação, Araraquara, v. 16, n. 4, p. 2852-2871, out./dez. 2021. e-ISSN: 1982-5587 
al anonimato y al olvido todo lo que rompe los estándares impuestos. Por el proyecto de modernidad traída por los colonizadores. Hoy, sin embargo, estos grupos y sus Maestros han recibido la atención de músicos urbanos, investigadores y productores culturales, cuyas obras han contribuido al surgimiento de proyectos colectivos e individuales que toman las prácticas de las Bandas Cabaçais como fuentes de conocimiento, prácticas y otras formas de existir culturalmente. Este estudio cualitativo, por lo tanto, destaca algunas experiencias narradas por algunas instrumentistas para entender por qué prácticas educativas aprenden, transmiten, aprenden y dan un nuevo significado a las bandas cabaçais. La recolección de datos se realizó a través de conversaciones en whatsapp. Esperamos que los ejemplos en lienzo inspiren y despierten el interés de muchas otras personas por el arte de la calabaza.

PALABRAS CLAVE: Educación. Banda Cabaçal. Prácticas educativas. Cultura popular.

ABSTRACT: The traditional Cabaçais Bands, also called Pifanos Bands, hegemonically constituted by men, are instrumental music groups which have existed in Brazilian Northeast since the colonial period. Linked to popular catholicism, they do not dispense opportunities to free their Brazilianness from capitalist dungeons, which, among other things, deny plurality, silence knowledge, do not recognize other educational practices and condemn to anonymity and forgetfulness everything which do not contemplates the standards imposed by the modernity project. Nowadays, however, these groups and their masters have received attention from urban musicians, academic researchers, and cultural managers, so that collective and individual musical new musical projects have emerged in all Brazilian states, having the Cabaçais Bands as a referencial of musical knowledge, practices and other ways of existing in a social reality. This qualitative research, therefore, highlights some musicians experinces to understand how they and other musicians learn, transmit and give new meaning to the cabaçal music bands. We hope the examples in evidence here, collected by whatsaap, inspire, and arouse interest of many other musicians in music bands focused here.

KEYWORDS: Education. Cabaçais Bands. Educational practices. Popular culture.

\section{Introdução}

É fundamental abrir outras veredas, mostrar que é possivel transitar pelas brechas, compartilhar possibilidades de outras histórias.

Belijane Marques Feitos (2021)

As Bandas Cabaçais, também conhecidas, dentre outros termos, como Bandas de Pífanos e zabumbas, estão espalhadas pelos estados da Bahia, Sergipe, Alagoas, Pernambuco, Paraíba, Ceará e Norte de Minas Gerais. Esses grupos, que remontam ao Brasil colônia, têm usos e funções vinculados ao catolicismo popular e, com algumas exceções, têm suas atividades

${ }^{4}$ Professora do Curso de Educação da Universidade Federal de Campina Grande, Campus Cajazeiras - Paraíba. Atualmente, é doutoranda do programa de Pós-Graduação em Educação da UFS. A fala em destaque foi gravada durante aula da disciplina Cultura Popular e Contemporaneidade. 
limitadas ao contexto rural, aparecendo, principalmente, nas novenas ${ }^{5}$ realizadas como pagamento de promessas assumidas junto ao sagrado. Em alguns casos, inclusive, há bandas que tocam apenas no dia do santo venerado pelo seu Mestre ou por algum outro fiel da sua vizinhança. Como explica Silva (2011, p. 70), o catolicismo português:

[...] nos trouxe uma série de tradições e festividades que construíram nosso calendário, nos legando folguedos como o Bumba-meu-boi que se desenvolveu no maranhão, Reisado, Cavalhada, Marujada, Chegança, Auto natalino, Carnaval, Festejos juninos e tantos outros, onde alguns se consolidaram como musicalidades típicas em alguns estados do Nordeste $[\ldots]$.

Nesse contexto musical religioso, com um repertório tradicional composto por benditos, valsas, marchas e baiões transmitido de geração em geração e classificado pelos pifeiros como sendo a música do começo do mundo ou como a música dos índios, ${ }^{6}$ as Cabaçais estão relegadas ao anonimato. Em sua constituição há elementos europeus, indígenas, africanos e árabes, fazendo delas um produto brasileiro híbrido. Com dois pífanos, uma zabumba e uma caixa de guerra, esses grupos caracterizam-se também por terem uma formação hegemonicamente masculina. As mulheres, em alguns casos, exercem uma participação efetiva na confecção da farda das bandas e, em todos as outras situações, na preparação do café da manhã, almoço e jantar para os músicos e para as pessoas que aparecem no dia da reza, cuja organização é também de responsabilidade feminina.

Através das nossas incursões no universo do pífano paraibano, nós temos percebido que o número das Bandas Cabaçais rurais tem reduzido drasticamente, revelando, dentre outras coisas, que as novas gerações não têm dado importância a esse patrimônio que um dia teve grande prestígio em suas comunidades. Diante dessa realidade, já encantados por tudo que já havíamos vivenciado com as cabaçais, decidimos, então, intervir em favor da dinamização dos grupos remanescentes no Sertão da Paraíba. Uma das estratégias foi introduzir alguns na programação de eventos realizados no contexto acadêmico e, sobretudo, por instituições promotoras de cultura, dentro e fora do estado. Outra ação que gerou bons resultados foi a distribuição de pífanos entre amigos instrumentistas. A intenção era despertar olhares de fora para o universo cabaçal que pudessem influenciar, entre familiares e comunidades de pifeiros de um modo geral, novas compreensões em relação às Cabaçais. Essas investidas também nos possibilitaram contatos com bandas, músicos, produtores e pesquisadores de outros estados; e foi justamente

\footnotetext{
${ }^{5}$ As novenas são eventos nos quais se rezam para um santo durante nove dias, nove horas ou nove semanas. No contexto das cabaçais, as rezas são feitas durante nove dias.

${ }^{6}$ Expressões extraídas de depoimento para Braga (2015), transcrito no livro Celebrações da Vida: História e Memória da Banda Cabaçal Os Inácios. Este livro é resultado da sua pesquisa de mestrado.
}

RIAEE - Revista Ibero-Americana de Estudos em Educação, Araraquara, v. 16, n. 4, p. 2852-2871, out./dez. 2021. e-ISSN: 1982-5587 
nesse caminhar que ficamos sabendo da existência em todo o Brasil de um expressivo movimento artístico musical urbano em torno da cultura do pífano.

O grupo de WhatsAap Pífano Livre Brasil, com mais de 150 participantes, dentre eles, Mestres, músicos profissionais e amadores, pesquisadores e produtores de cultura popular, nos revelou que, enquanto a Cabaçal dava os primeiros passos nas ruas de algumas cidades paraibanas, os pífanos já não eram mais novidade no asfalto de Fortaleza, Rio de Janeiro, Teresina, Norte de Minas, Florianópolis, São Paulo, Brasília e de tantas outras cidades dos estados brasileiros. Foi aí que conhecemos projetos musicais como: Pifarada Urbana - Fortaleza CE, Caju Pinga Fogo Teresina - PI, Trem de Doido - Minas Gerais, Mestre Zé do Pife e as Juvelinas, de Brasília, e os blocos de carnaval do Rio de Janeiro, São Paulo, Recife e de Brasília. Foram esses blocos, inclusive, que inspirou a fundação, em João Pessoa, do bloco carnavalesco de pífano, Avuô.

Com esse movimento contemporâneo envolvendo pesquisadores/as, produtores/as culturais e artistas da música, as cabaçais tradicionais ganharam mais visibilidade, de modo que tem sido crescente o número de instrumentistas, profissionais e amadores, espalhados pelo Brasil, que aprendem, ressignificam e vinculam os saberes, práticas e instrumentação cabaçais aos seus fazeres educativos e artísticos. Espiritualmente "pifanizadas", 7 essas pessoas passaram a desenvolver atividades individuais e coletivas em função da divulgação das Bandas Cabaçais e da inserção definitiva, sobretudo, do pífano, no contexto cultural urbano. Nesse novo panorama, a presença feminina tem rompido com a tradição patriarcal e também assumido o pífano ou algum outro instrumento da percussão cabaçal tradicional. Nesse movimento, homens e mulheres, no mesmo barco, deram origem ao que chamamos de pifeiros e pifeiras urbanos/as.

\section{O pífano ganha o asfalto pelas práticas experienciadas por pifeiras e pifeiros urbanos}

\section{[...] Às vezes você pensa que vai aprender a tocar pifano como um passatempo, mas, ele pode salvar a tua vida.}

Dentre outros aspectos vivenciados pelas Bandas Cabaçais tradicionais, destacamos algumas práticas, inclusive educativas, experienciadas no contexto urbano acima mencionado a luz de Brandão (2013) ao apontar que de um modo, ou de muitos cotidianamente, nos envolvemos com diferentes processos educativos para aprender, ensinar, aprender-ensinar, saber,

\footnotetext{
${ }^{7}$ Neologismo para indicar estado de encantamento.

${ }^{8}$ Fala extraída de conversa de Kika Brandão em live realizada e publicada no instagram @tremdedoido_,no dia 25 set. 2020.
} 
fazer, ser ou para conviver. A seu ver, a educação tem a missão de transformar sujeitos e mundos em alguma coisa melhor. Desta forma, selecionamos trechos de conversas que tivemos, através de whatsapp, com as amigas pifeiras urbanas Tauana Queiroz, Rafaela Abreu, Vitória do Pife e Dani Neri, para compreendermos como a formação cabaçal transformou os fazeres e o modo de ser de cada uma. $\mathrm{O}$ texto também evidencia como elas aprendem, ensinam, ressignificam, abrem clarões para a cultura cabaçal e fazem dela um componente fundamental na cena cultural contemporânea de suas comunidades.

\section{Tauana Queiroz e Rafaela Abreu: ressignificando a percussão cabaçal em Teresina - PI}

A ancestralidade e potência do pife é sentida dentro de nós, por isso a sonoridade típica nos transporta pro interior, pra raiz de onde viemos. Tauana Queiroz (10 mar. 2021).

Eu acho que o nosso papel como uma banda de pifano urbana é direcionar cada vez mais os olhares do nosso público para essa cultura que ainda está vivíssima. Rafaela Abreu (12 mar. 2021).

Foi através do amigo Léo Mesquita, pifeiro urbano piauiense, que em março de 2021, através do whatsapp, conhecemos a zabumbeira, cantora e compositora Tauana Queiroz e a pesquisadora, bailarina, intérprete e percussionista Rafaela Abreu. Inicialmente recebi, das duas, confirmação positiva que topariam conversar sobre as experiências delas com a cultura cabaçal. Trechos de suas falas aparecem ao longo desse texto, destacados em itálico. Considerando a inexistência da tradição cabaçal no Piauí, segundo Léo, começamos perguntando às duas como foi então que a música cabaçal chegou para elas e como ambas dialogavam com essa tradição que vinha de outros lugares. Pelas suas respostas, os primeiros contatos com grupos tradicionais foram através de Maguim do Pífano, músico idealizador da banda Caju Pinga Fogo, da qual as duas são percussionistas. Maguim trouxe como referência primeira a Banda de Pífano de Caruaru, liderada pelo Mestre Biano. Essa banda, para Rafaela, é o seu ponto de partida - que sempre será ponto de chegada, dada a grandiosidade do trabalho e força de uma criação capaz de mudar a história da música brasileira a partir da notoriedade possibilitada pelo Tropicalismo do disco Expresso 2222, gravado em 1972, pela Philips Records, cujo repertório traz a música Pipoca Moderna, do Mestre Sebastião Biano, letrada por Caetano Veloso e gravada por Gilberto Gil no referido álbum.

Além da banda da família Biano, Tauana e Rafaela ampliaram as suas lentes para tantas outras igualmente valiosas, com destaque para os Irmãos Aniceto, Zabé da Loca, Banda Dois Irmãos, Princesa do Agreste e Banda Zé do Estado. Somado a esses trabalhos 
tradicionais, alguns grupos não tradicionais também fizeram as percussionistas lançarem o olhar para o Pife Muderno liderado pelo flautista Carlos Malta e para a banda brasiliense Mestre Zé do pife e as Juvelinas.

Quando falamos sobre o processo de aprendizagem da música cabaçal diante da falta de grupos tradicionais inseridos no território piauiense, Tauana nos disse que nunca tinha estudado percussão antes da banda Caju Pinga Fogo. O seu processo de aprendizagem seguiu uma das principais metodologias vivenciadas pelos pifeiros tradicionais, ou seja, aprender tocando em grupo, tanto durante ensaios quanto durante as apresentações. Ver outros músicos em ação, sobretudo, tocando zabumba, inclusive zabumbeiros das cabaçais tomadas como referências, foi uma das outras estratégias de aprendizagem.

Sobre a sonoridade cabaçal, a percussionista entende que certamente já estava em sua memória auditiva. Para ela, quem é do Nordeste reconhece o seu som, faz assimilações, mesmo que não tenha familiaridade com os instrumentos. A partir daí, surgiu o interesse em pesquisar, e foi:

[...] junto com a pesquisa teórica e sonora, seja consumindo conteúdos fonográficos, audiovisuais, ou frutos da oralidade, que fomos adentrando as peculiaridades dos ritmos, dinâmicas, modos de composição, toques de cada instrumento que compõe a base de uma tradicional banda de pífanos. A partir dai, naturalmente fomos instigados a misturar nossas vivências contemporâneas com as originais e tradicionais para criar composições próprias, com referências do nosso lugar e tempo (TAUANA, 10 mar. 2021).

Mesmo existindo o distanciamento físico e espacial com a realidade das bandas tradicionais, essas experiências fizeram as percussionistas perceberem a força da música cabaçal. Para a zabumbeira de voz e composições maravilhosas, é lindo descobrir tanto, no que para os desatentos pode parecer uma simples formação musical. Tauana entende que o propósito de uma Banda de Pífanos é perpetuar um estilo de vida, tradições de um povo, o alcance e a capacidade de representatividade que o pífano possui. Para ela, essas bandas apresentam potência na criação, no experimentalismo, na ousadia e improvisações únicas e geniais, que são eternizadas nas melodias, no comportamento, nas reflexões sobre a realidade do povo nordestino e na relação entre homem e natureza. Esse tipo de relação, como lembra José Jorge de Carvalho, anunciada por Antônio Bispo (2015), propõe um modelo alternativo de sociedade baseada na biointeração comum às comunidades quilombolas, aos terreiros de matriz africanas e aos povos pindorâmicos. 
Sobre a presença feminina nos grupos urbanos, Tauana foi enfática em dizer que na atualidade, embora as mulheres tenham mais autonomia e ocupado os espaços sociais que antes lhes eram negados, ainda não é fácil se dizer artista. Rafaela, por sua vez, entende que:

[...] a presença feminina surge de uma forma bem natural como aconteceu com as Juvelinas, que tocam junto com o Mestre Zé do pife. Eles se conheceram durante aulas e oficinas que o Zé do Pife dava na universidade de Brasilia e agora eles têm um grupo. E é sobre isso, a cultura é algo mutável e ela vai se modificando com o passar do tempo, com as diversas interações com cada indivíduo (RAFAELA, 12 mar. 2021).

Essas mudanças, comuns aos processos de hibridismos culturais, tornam-se muito mais presentes na contemporaneidade com o advento da internet. Se a Banda Cabaçal já nasceu híbrida, as ressignificações dos seus saberes e fazeres, sobretudo, fora do contexto tradicional rural, adquiriram uma dinâmica contundente na promoção do surgimento de outras estéticas sonoras que revelam o diálogo entre o rural cabaçal e a música dita urbana. Tauana, diante dessa realidade, acredita não ser possível reproduzir a linguagem original do pífano. Para ela, isso se dá pelo fato de pertencerem a uma juventude urbana, constituída por outras formas de ser e estar no mundo. Ela nos explica dizendo:

Não temos vivência pra dialogar com a cultura do pífano com a mesma verdade que as pessoas que habitam o interior de onde surgiu a tradição o fazem. Nem acredito que isso seja algo que possa ser adquirido, nem com tempo, nem com estudo. Essa compreensão torna possível o diálogo entre o tradicional e o não tradicional (TAUANA, 10 mar. 2021).

É também nesse sentido de reorganização que Rafaela se reporta ao encontro entre o Mestre Zé do Pife e as musicistas da banda As Juvelinas. Neste caso, tanto ele quanto elas se reorganizaram musicalmente. Para o Mestre, o novo grupo é uma estratégia de (re)existência. Para elas, uma abertura a outras formas de experimentar e produzir saberes musicais e extramusicais que rompam com o puramente acadêmico.

Com base no pensamento das percussionistas piauienses, as práticas e saberes dos Mestres e Mestras da cultura popular conquistam a valorização, respeito e possibilidade de ressignificações em diferentes contextos, a exemplo de Caruaru, onde mora Vitória do Pife.

\section{Práticas educativas cabaçais que constituem a pifeira e educadora Vitória do Pife}

[...] todo som é bom, mas o som de uma banda de pife me toca no cerne da alma. Vitória do Pife (4 abr. 2021). 
Vitória do Pife é uma jovem artista da cidade de Caruaru - PE. O interesse em conversar com ela se deu a partir de uma live que ela participou no instagram @bandaavuo. Da mesma forma que fizemos com Tauana e Rafaela, falamos do nosso trabalho e perguntamos se ela toparia uma conversa especificamente sobre o seu fazer artístico e profissional a partir o pífano. Com o seu aval, inclusive para publicarmos, conversamos um pouco pelo Whatsapp e depois ela nos encaminhou um relato versando sobre a sua história com esse instrumento. Trechos do seu texto também são destacados aqui.

Diferentemente das piauienses acima destacadas, a caruaruense Vitória do Pife, embora não pertença a uma família cabaçal, teve o seu fazer musical iniciado diretamente com o pífano e com um Mestre tradicional. Aos 17 anos, pediu um instrumento ao pai que, por trabalhar em uma padaria vizinha da oficina de São João do Pife, encontrou facilidade em atender ao pedido da filha comprando-lhe um pífano. Segundo Vitória nos falou, começou a frequentar a oficina do Mestre acompanhada de amigas e amigos que na época também voltaram seus olhos para as bandas de pífanos. Vejamos o que ela nos disse sobre essas primeiras experiências cabaçais:

[...] Inicialmente pedia pra ele me ensinar determinada música. Ele tocava pra eu ouvir. Depois tocava mais lento pra eu tentar repetir os movimentos que ele fazia. Como eu não conseguia, ele tocava um pouco mais lento. Depois disso eu pedia pra ele tocar novamente, filmava e estudava em casa. Quando eu já estava tocando a música, eu voltava lá pra mostrar pra ele e repetia o processo com uma nova música. [...] Íamos lá com frequência e até iniciamos uma bandinha, que Seu João emprestava os instrumentos e os ensaios aconteciam em sua oficina. Por motivos pessoais, infelizmente, a bandinha não vingou (VITÓRIA DO PIFE, 04 abr. 2021).

Como pode ser percebido, assim como normalmente acontece no interior dos grupos tradicionais, Vitória aprendeu a tocar a partir da observação e tocando junto com o Mestre. O Youtube ajudou nesse processo, como também tem ajudado a alguns Mestres e aos seus jovens que se interessam pela arte que os seus mais velhos produzem. A sua primeira bandinha não vingou, mas, mesmo assim, ela não largou a companhia do instrumento, porque, já nas suas primeiras vivências com o pífano se sentiu tocada no cerne da carne. Jorge Larrosa (2020) diria que ela experenciou esses acontecimentos. Para ele, experiência é aquilo que nos toca, nos atravessa, nos faz sentido, justamente como aconteceu com Vitória do Pife ao vivenciar o pífano.

Para essa jovem, o pife nunca foi brinquedo e nem passa tempo, mas sim, um instrumento que logo passou a ser sinônimo de vida, alegria, paz, amor, amizade, sobrevivência e, por isso, simbólico. BOFF (1998) nos explica que o termo simbólico tem o sentido de lançar as coisas de modo que permaneçam juntas. Daí, em nome da cultura popular, Vitória agarrar-se 
ao pífano e associá-lo a trabalhos de amigos circenses na labuta em faixas de pedestres, no centro de Caruaru e em ônibus urbanos.

Ainda em 2017, já querendo mais, passou a frequentar as aulas de pífanos ministradas na Casa do Pife que fica na Estação Ferroviária de Caruaru. Outra estratégia importante no processo de aprendizagem foi inserir-se na Orquestra de Pífanos de Caruaru, onde aprendeu muito mais durante as apresentações ao lado de Mestres como: Peba do Pife, Edmilson do Pífano, João do Pife, Marcos do Pife, Zau do Pife, Biu do Pife, Antônio do Pífano, Vavá do Pife e banda Zé do Estado. Com esse time de estrelas tocou ao lado de Elba Ramalho e do jazzista pernambucano, Alexandre Rodrigues, que também é luthier de pífanos e pifeiro

A maturidade de Vitória proporcionou o engajamento da sua prática artística, resultando na criação, com algumas amigas, do grupo Camoranas, com o qual fizeram apresentações em ruas, bancos e praças públicas. Segundo a pifeira, esse projeto musical ressaltava o empoderamento feminino no meio artístico. Era o pífano dizendo que o feminino também tem espaço na Banda Cabaçal, como bem provou Zabé da Loca, pernambucana que veio ainda criança para a Paraíba. Zabé morou e morreu aos 93 anos na zona rural de Monteiro. E é justamente a pifeira Zabé da Loca, referência de Mestra de pífano tradicional, o que faz Vitória do Pife pensar na igualdade de gênero e sentir o senso de responsabilidade na afirmação de sua identidade. Por isso o orgulho de ressaltar que o pífano hoje representa o seu sustento. Para ela, é sempre importante destacar a representatividade feminina e a importância do posicionamento da mulher nos espaços de cultura, pois a mulher também é a voz do povo e diz muito sobre a história, infelizmente pouco contada. Hegemonicamente os pífanos das Bandas Cabaçais tradicionais são executados por homens, então, para Vitória do Pife ser a única mulher integrante de Banda de Pífanos em Caruaru é uma quebra de paradigmas. Sobre essa questão ela acrescenta:

Não me sinto diferente, me sinto apenas encorajada, cada vez mais a fazer o que amo. Independente do meu gênero, independente do gênero que se apresenta, o que importa é toda essa mística. Digo isso, mas na prática enfrentamos dificuldades palpáveis e acredito que isso nos fortalece enquanto mulheres, enquanto cidadãs e enquanto profissionais. (VITÓRIA DO PIFE, 4 abr. 2021).

É muito lindo ver a poesia voando do pífano de Vitoria, assim como é muito lindo ver a poesia falando pelas suas palavras quando nos diz que:

A sonoridade das bandas de pifanos me encanta por demais, e toda vez que escuto um álbum da Banda de Pífanos de Caruaru, aquilo me remonta a algo que não sei explicar, é como um sonho, algo subjetivo que me diz

RIAEE - Revista Ibero-Americana de Estudos em Educação, Araraquara, v. 16, n. 4, p. 2852-2871, out./dez. 2021. e-ISSN: 1982-5587 
algumas coisas que só consigo transmitir quando toco, quando ensino, quando vejo Seu João e Seu Marcos na oficina, construindo pífanos ou zabumbas, fazendo aquilo com tanto amor. Quando vejo a banda Alvorada do Mestre Vavá, ou a Banda Zé do Estado, com Zé Gago e Seu Bastos quebrando tudo e Mestre Tonho sempre sereno. Uma Banda de Pifanos é um conjunto de histórias. Não é qualquer pessoa que pega uma caixa e faz o toque, não é qualquer zabumbeiro que toca a zabumba e reproduz aquela raiz. Banda de Pife é história, é a história dos componentes e de um tempo (VITÓRIA DO PIFE, 04 abr. 2021).

O fazer cabaçal de Vitória não se limita a tocar. Certo dia, a partir de suas aparições em logradouros públicos como pifeira, foi procurada por um amigo pifanizado que estava querendo aprender a tocar o instrumento. Nasceu, então, a professora Vitória do Pife, que depois também virou luthier e compositora. A sua essência de mulher ativista lhe provocou a usar parte do seu tempo para desenvolver projetos de musicalização com crianças e adolescentes de Caruaru.

Hoje, com a experiência adquirida durante o seu processo de aprendizagem, a professora Vitória, com dois anos de atuação, tem desenvolvido uma metodologia que parte das dificuldades que ela teve durante a sua trajetória como aprendiz iniciante. Dessa forma, dependendo muito do que a pessoa está buscando, ensina, pela oralidade, a feitura de pífanos, métodos de respiração, embocadura, nota por nota e escalas. Exercita a escuta, a observação e a repetição; tudo isso, inicialmente, com uma música mais rítmica do que melódica, estrategicamente utilizada para manter a motivação, porque o pífano não é instrumento fácil. Em suas aulas, a professora Vitória busca a transformação das pessoas, daí ensinar a música também como forma terapêutica. Neste contexto educativo, pede para os alunos produzirem seus próprios pífanos. A intensão é estabelecer o primeiro vínculo afetivo com o instrumento e com a música cabaçal.

Para ela, além desse vínculo, o pífano trouxe a possibilidade de perceber o seu corpo, visto que, só em trabalhar a respiração já acalma e você leva pro dia a dia. Todo mundo que toca pife é zen, e eu atribuo isso ao fato de usar muito a respiração para tocar o instrumento.

Com essa dinâmica, a música entra como ferramenta, não para formar profissionais da música, mas, para chegar naquele aluno que tem vulnerabilidade social, que já é excluído e assim conseguir inclui-lo na sociedade através do forte papel social que a música tem, de conectar as pessoas, do mesmo jeito que um dia o pífano funcionou com ela. 


\section{Dani Neri: da flauta europeia à popular para alegria pifanizada das ruas de Brasília}

Depois de algum tempo fiquei sabendo que inspirei outras mulheres. [...] $E$ um orgulho pra mim, ser parte de uma representatividade de mulheres no pife. Dani Neri (7 abr. 2020).

As vivências com o pífano urbano nos fazem perceber que ele jamais será igual ao pífano rural. Diferenciam-se na forma de aprender, de tocar, nos objetivos e crenças dos instrumentistas, nos sentidos atribuídos às práticas musicais, nas afinações dos instrumentos, nos repertórios, nos palcos, nas plateias etc. Nas bandas tradicionais rurais, os instrumentistas urbanos vão buscar inspiração para constituição de uma nova estética que, inclusive, tem animado e orgulhado os Mestres. Animam porque eles sabem que as bandas urbanas são máquinas musicais que podem abrir caminhos para que as bandas tradicionais possam pular cercas e também caminhar pelo asfalto. Orgulham porque os Mestres percebem o quanto a música que fazem tem sido inspiradora para que existam tantos outros trabalhos, em tantos outros lugares. Quando os Mestres percebem que tem gente interessada na arte que eles produzem, abrem sorrisos, enxergam novas possibilidades de resistência e existência para a sua arte.

Assim como aconteceu com as musicistas acima mencionadas, o pífano também atravessou o caminho da juventude de Brasília. Ficamos sabendo disso pelo grupo de WhatsAap, PifeLivreBrasil, através do qual fizemos contato com a flautista/pifeira, atriz e educadora Dani Neri. Explicamos para ela que pretendíamos escrever este trabalho e gostaríamos de ter um depoimento dela sobre a cena do pífano na capital do país e, sobretudo, sobre a participação feminina nesse contexto.

Assim como procedeu Vitória do Pífe, Dani Neri topou e nos encaminhou mensagem com a sua narrativa. Com o seu texto, para a nossa surpresa, ficamos sabendo que tinha bastante gente tocando pífanos por lá, homens e mulheres. Ela já conhecia o Mestre pernambucano Zé do Pife, que morava em Brasília e costumava tocar e vender, para a comunidade universitária, os instrumentos que fabricava. $\mathrm{O}$ contato direto com o pífano veio em 2004, através de amigos que também conheciam Seu Zé e se encantaram pelo instrumento e pela música que o Mestre tocava. Desta forma, com o Mestre, o amigo e músico, Davi, aprendeu a fabricar pífanos de PVC e, com os amigos, decidiu investir em novas possibilidades musicais a partir desse instrumento.

Dos estudos cabaçais experienciados, veio a ideia de concretizar o desejo de criação de uma cena carnavalesca que ocupasse as ruas de Brasília. Nada mais de viagens para Olinda, 
Recife e Rio de Janeiro; essa seria a oportunidade de fazerem as ruas de Brasília serem um pouco mais brasileiras. Surgiu, assim, o bloco Ventoinha de Canudo, que, diferentemente dos outros mais antigos da cidade, é mais orgânico, acústico e poético. Quando Dani nos disse da existência desse movimento de ocupação urbana, há 18 anos, ficamos em estado de poesia, como diz o cantor e compositor paraibano Chico César no álbum lançado em 2015. Nunca havíamos imaginado que o pífano estava operando pelas frestas do concreto "candango". Ficamos bem felizes em saber que em Brasília tinha gente comprometida com a brasilidade, com a liberdade de expressão e com a pluralidade cultural. O Ventoinha de Canudos, o bloco das crianças, como Dani Neri falou, representa a realização de um sonho de todo ano, nos domingos e terças feiras de carnaval, ir para a rua, agregar pessoas de todas as idades e saírem livres com suas fantasias, ocupando as ruas da cidade e dançando ao som dos pífanos.

Como ela explicou, a cidade tem muito espaço e pouca ocupação de rua. Como tudo é muito grande, seria tudo de bom fazer esse movimento de ocupar praças, comércios, sem um roteiro definido. Fora de qualquer padrão carnavalesco, fora de circuito fechado. Amamos essa ideia de possibilitar que o popular seja realmente popular. No início, Dani Neri era a única mulher do grupo, mas logo chegaram outras que ocuparam, inicialmente o estandarte, depois a percussão e, mais pra frente, os pífanos. O carnaval de Brasília ganhou uma nova fisionomia. Nada plugado, um carnaval pifanizado, bebendo da fonte do Mestre Edmilson do Pife, dos Irmãos Aniceto, de Carlos Malta, Luiz Gonzaga, Hermeto Pascoal, Gilberto Gil, Pixinguinha, Jackson do Pandeiro, Baden Powell e da Banda de Pífanos de Caruaru. Uma ação que resultou em um processo de hibridação, através do qual a música tradicional cabaçal, dialogando e fundindo-se com os referenciais musicais dos/as instrumentistas, também dá o tom do repertório do carnaval.

Os integrantes do Ventoinha são alunas/os, ex-alunos/as e professores/as da Escola de Música de Brasília e da Escola de Choro Raphael Rabello. Os encontros dos seus 4 pífanos com a zabumba, caixa e pratos acontece basicamente algumas semanas antes do carnaval, para ensaiar e construir os novos chapéus e camisetas do bloco. O Ventoinha de Canudo é a nossa festa! Nosso rito! Nossa militância carnavalesca! A essas palavras de Dani Neri acrescentaríamos que o Ventoinha de Canudo é uma ação libertária, que pelas frestas do carnaval elitista e excludente de Brasília combate o silenciamento da nossa brasilidade musical. O grupo a cada ano vem formatando um percurso que já invadiu, inclusive, a tesourinha, um dos símbolos arquitetônicos da modernidade brasiliense. Dani Neri lembra

\footnotetext{
${ }^{9}$ Nome atribuído a cada um dos primeiros habitantes de Brasília. Usamos aqui como sinônimo de brasiliense.
} 
que essa via é ocupada somente por carros e, por isso, provoca uma grande explosão de alegria quando o bloco chega embaixo dela.

Pensando com Simas $(2020)^{10}$, essa explosão de alegria se dá em função da rua ser um lugar de tensão entre a colonialidade e a brasilidade. Com este entendimento, Boff (2000, p.102, 103) explica que a rua, além de ser um lugar físico, é também “[...] o conjunto das relações de trabalho, de luta pela vida, de hierarquias e ordenações sociais entre indivíduos anônimos e estrutura que formam a esfera do público e do oficial [...]”. No entanto, como ele mesmo acrescenta, “[...] neste espaço há também rituais e celebrações como feriados, as festas nacionais e as festas populares, quer religiosas (dos padroeiros) ou seculares (dos carnavais e dos campeonatos de futebol)" (grifos do autor). E é justamente no período momesco que o Ventoinha de Canudo desenclausura a brasilidade, pula a cerca e domina um território onde os corpos domesticados para o trabalho só podem trafegar se for de carro, para pegar no arado. Um espaço pensado para servir a um projeto de modernidade perverso que não se permite enxergar um Brasil construído a partir da sua brasilidade e que, a partir do alvorecer da modernidade, no século XVI, é movido pela “[...] vontade obsessiva e desmesurada de concentrar poder, de enriquecer, de conquistar novas terras e de subjugar outros povos" (BOFF, 2.000, p. 31), traduzido, como ele diz, em colonialismo, em imperialismo e na vontade de homogeneização material, cultural e religiosa. Ocupar a Tesourinha e enchê-la de alegria, então, é uma forma de exercer a liberdade de ser, existir, ir, vir, dizer, tocar, dançar, mesmo que temporariamente.

Para Simas, no vídeo acima mencionado, refletir sobre a cultura de rua requer também uma reflexão sobre a diáspora, a qual descreve como sendo "um fenômeno de desagregação, de quebra de pertencimento, de quebra de laços de identidade, de rede de proteção social," mas que, por outro lado, ainda segundo esse historiador, “[...] é também um fenômeno de reprodução daquilo que foi perdido. [...] Se a diáspora dispersa, a cultura produzida por ela agrupa. Ela cria outras formas de proteção social”.

A construção de Brasília, por exemplo, recebeu, sobretudo, pessoas que buscavam tempos melhores longe dos períodos de estiagem nos sertões nordestinos. Pessoas que se desvincularam de suas raízes e que perderam a socialização com os seus, passando a viver em uma realidade onde a existência convive diariamente com a sede de poder, com o individualismo, a competição. É nesse contexto que projetos como o do Ventoinha de Canudo criam estratégias para lidar com o precário. A rua, pensando novamente com Simas (2020),

${ }^{10}$ FAU ENCONTROS: Simas, Luiz Antônio. O Encantamento das Ruas. Acesso em: https://www.youtube.com/watch?v=3ldM5QxM4h0. Acesso em: 02 ago. 2021.

RIAEE - Revista Ibero-Americana de Estudos em Educação, Araraquara, v. 16, n. 4, p. 2852-2871, out./dez. 2021. e-ISSN: 1982-5587 
neste sentido, é o "espaço de construção de cultura de frestas de brechas. [...] A rua como ponto de encontro, de sociabilidade, de rede de proteção social" contra a modernidade/colonialidade.

Além disso, no Ventoinha de Canudo há dois aspectos importantes. O primeiro é que se trata de um projeto pensado para garantir um cortejo no qual as crianças são também protagonistas. Ressalto as crianças porque o projeto de modernização não dialoga com esse segmento social quando pensa os seus quereres, de modo que tratora os espaços urbanos que poderiam ser ou já foram lugares onde poderíamos ver meninos e meninas correndo, jogando bila, brincando de amarelinha, de toca, jogo de castanha, pipa e etc. O segundo aspecto é a presença feminina puxando o bloco. Quando Dani Neri começou a tocar pífanos em 2004 e participou da fundação da banda do bloco, não tinha noção do que significava uma mulher tocando pífano no meio de um monte de homens. Depois de algum tempo ficou sabendo que inspirou outras mulheres a tocar. Diante disso, a pifeira orgulha-se de ter contribuído com a criação de uma representatividade de mulheres no pífano.

A partir da invenção de uma tradição em torno do carnaval e do pífano, em contraataque, também combate o patriarcalismo que, segundo Boff (2020), teve as suas raízes lançadas quando o homem da caverna se aventurou na conquista desse mundo exterior que ainda insiste em dominar, embora o feminismo tenha "desmascarado a presença do poder masculino em todos os campos da vida familiar e social, nas expressões da linguagem, na formulação dos saberes e na instituição de ritos e tradições, denunciando o patriarcado como poder opressor da mulher e do próprio homem" (BOFF, 2000, p. 27). Boff ainda complementa dizendo que essa conjuntura tem obrigado o masculino e a cultura a promoverem relações mais inclusivas e participatórias. É por isso que, independentemente de quem sopra os pífanos, homens ou mulheres, no Ventoinha de Canudo, o poder é exercido pela alegria trazida pela música, pela espontaneidade, pelo prazer de praticar um carnaval de rua.

Sobre as práticas musicais exercidas por Dani Neri, é importante também ressaltarmos que a musicista agrega o pife aos seus trabalhos com educação, teatro e produção cultural. Ela, que é integrante da Agrupação Teatral Amacaca, dirigida pelo Mestre Hugo Rodas, em seus projetos pessoais, além de aulas particulares, realiza oficinas de teatro e música para grupos de crianças, jovens e adultos, apresentações e oficinas em escolas, trabalha com atuação, criação, direção e sonoplastia de espetáculos e participa de projetos sociais com criança e jovens de regiões periféricas. Como ela faz questão de enfatizar, sempre tendo o pife como parceiro. Para a musicista/atriz/produtora e educadora, essas são contribuições que 
geram novas possibilidades de performances e desenvolvimento criativo, tanto para ela, quanto para quem experiencia as suas aulas. Por isso, em Brasília, muitas mulheres, inspiradas nos projetos de outras, tocam, passam chapéu e vendem suas aulas, inclusive nas diversas Cidades Satélites do Distrito Federal. Catherine Walsh (2018) ${ }^{11}$ diz que ser decolonial é um projeto de vida, e que é importante vivê-la de forma diária, senti-la e criar espaços dentro das fissuras sociais. Nesse sentido, as práticas das pifeiras de Brasília são exemplos a serem seguidos no processo de decolonização de saberes, fazeres culturais e de espaços urbanos onde, embora propícios, a poesia não tem vez.

Conhecermos o Ventoinha de Canudo e as coisas bonitas que o grupo propicia a partir do pífano é uma grande alegria para nós que também somos apaixonados por esse instrumento rústico que, com a rabeca e a viola, forma a tríade instrumental da cultura popular nordestina. Mais ainda é a alegria de sabermos que o pífano definitivamente entrou no cotidiano da capital do país graças às ações de um Mestre do Sertão do Pernambuco, Seu Zé do Pife, que ensinou e inspirou o surgimento de projetos como o Ventoinha de Canudo e a banda Mestre Zé do Pife e as Juvelinas. Esse grupo liderado por um Mestre cabaçal que saiu da sua terra deixando família e um grande amor chamado Banda Cabaçal.

Para amenizar a dor da partida, levou na bagagem um companheiro da vida toda, o seu pífano. Depois de circular por outras veredas, Seu Zé do Pife chegou em Brasília e descobriu a Universidade. Tiro certeiro. Ali estavam pessoas de braços, corações e almas abertas ao encantamento, à vivência, à experiência cabaçal. Como desdobramentos, surgiram pifeiros e pifeiras e, em especial, o grupo, já citado, Mestre Zé do Pife e as Juvelinas, estabelecendo uma relação dialógica entre os saberes tradicionais rurais que constituíram o Mestre e os saberes urbanos carregados pelas instrumentistas Kika Brandão (pífano e pandeiro), Maísa Arantes (pífano e rabeca), Naira Carneiro (pífano e sanfona), Andressa Ferreira (caixa), Isa Flor (zabumba), Gotcha Ramil (rabeca) e Luciana Bergamasch (triângulo e prato), que o acompanham e cantam.

O êxodo rural do Mestre parece ter sido traçado pelos "Deuses Cabaçais". O pífano precisava ganhar o asfalto da capital do país, grande símbolo do poder que opera nessa terra que já foi colônia e que desde então respira cotidianamente a colonialidade. O pífano de Seu Zé parece ter recebido a missão de decolonizar praças, feiras, eventos e até espaços da Universidade de Brasília, onde a colonialidade do saber provavelmente nunca tenha falado e permitido a leitura ou a escrita sobre a epstemologia cabaçal. Imaginamos os praticantes do

${ }^{11}$ Disponível em: https://www.youtube.com/watch?v=k66AztrWDAw. Acesso em: 08 jun. 2021.

RIAEE - Revista Ibero-Americana de Estudos em Educação, Araraquara, v. 16, n. 4, p. 2852-2871, out./dez. 2021. e-ISSN: 1982-5587 DOI: https://doi.org/10.21723/riaee.v16i4.15685 
academicismo tradicional e eurocentrado incomodados pelo atrevimento desse nordestino negro, pobre, sem o domínio da escrita e sem qualquer conhecimento musical teórico e erudito, adentrar a academia se dizendo Mestre, afastando o academicismo, abrindo frestas, ocupando espaços e, com uma metodologia própria, ensinando a jovens músicos os saberes que um dia aprendera no seu torrão natal, tocando com outros Mestres. A metodologia de Seu Zé do Pife, inclusive, em 2010 virou pesquisa de mestrado, depois que Valéria Levay Lehmann da Silva perguntou para ele: "Seu Zé, qual é a sua didática?"

Esse trabalho, no campo da educação musical, vinculado ao Programa de PósGraduação em Música do Instituto de Artes da Universidade de Brasília e norteado pelo querer saber quais as práticas e formas de aprendizagens que ocorriam e como ocorriam nas oficinas de pífanos realizadas na UNB, desde 2007, tendo o Mestre Zé do Pife como educador, fez de Valéria Levay uma observadora participante, para que pudesse compreender que nas oficinas de pífanos em questão as práticas e formas de aprendizagem não obedeciam a uma metodologia pronta. Seu Zé ensina pelo método que aprendeu os saberes comunitários, de modo que os seus educandos precisam observar o Mestre tocando, imitar os movimentos dos seus dedos, da cabeça, do olhar, tocar com ele e ouvir as suas histórias. As práticas educativas vivenciadas nos processos de aprendizagem do saber comunitário, como nos diz Brandão (2013, p. 20), envolvem:

[...] situações pedagógicas interpessoais, familiares e comunitárias, onde ainda não surgiram técnicas pedagógicas escolares, acompanhadas de seus profissionais de aplicação exclusiva. Os que sabem: fazem, ensinam, vigiam, incentivam, demonstram, corrigem, punem e premiam. Os que não sabem espiam, na vida que há no cotidiano, o saber que ali existe, veem fazer e imitam, são corrigidos, punidos, premiados e, enfim, aos poucos aceitos entre os que sabem fazer e ensinar, com o próprio exercício vivo do fazer. (2000, p. 20).

No caso das oficinas de Seu Zé, essas estratégias de ensinar e aprender se repetem e se complementam com as anotações e filmagens feitas pelos pifeiros aprendizes. O bacana disso, para nós, é a prática de 'tocar de ouvido,' romper com o padrão de ensino-aprendizagem de música na academia. Essa metodologia pode, inicialmente, até dificultar para as/os aprendizes que dependem da escrita musical erudita, mas, por outro lado, possibilita, dentre outras coisas, que todos também experienciem a música com o corpo e com a alma, de modo que esse acontecimento faça sentido.

Para compreender por que dizemos que a metodologia do Mestre Zé do Pife rompe com os padrões da academia, basta observar o que aponta Pereira (2014, p. 93-94) ao analisar 
a constituição histórica do ensino superior de música no Brasil. O seu estudo identificou características que vinculam profundamente o ensino de música à instituição conservatorial. Segundo afirma, nesse padrão conservador o ensino tem vida:

[...] aos moldes do ofício medieval - o professor entendido, portanto, como mestre de ofício, exímio conhecedor de sua arte;

- o músico professor como objetivo final do processo educativo (artista que, por dominar a prática de sua arte, torna-se o mais indicado para ensiná-la);

- o individualismo no processo de ensino: princípio da aula individual com toda a progressão do conhecimento, técnica ou teórica, girando em torno da condição individual;

- a existência de um programa fixo de estudos, exercícios e peças (orientados do simples para o complexo) considerados de aprendizado obrigatório, estabelecidos como meta a ser alcançada;

- o poder concentrado nas mãos do professor - apesar da distribuição dos conteúdos do programa se dar de acordo com o desenvolvimento individual do aluno, quem decide sobre este desenvolvimento individual é o professor;

- a música erudita ocidental como conhecimento oficial;

- a supremacia absoluta da música notada - abstração musical;

a primazia da performance (prática instrumental/vocal);

- o desenvolvimento técnico voltado para o domínio instrumental/vocal com vistas ao virtuosismo;

- a subordinação das matérias teóricas em função da prática;

- o forte caráter seletivo dos estudantes, baseado no dogma do "talento inato" (PEREIRA, 2014, p. 93-94).

Essas características, como podemos observar, evidenciam um modelo que corresponde ao ensino de conhecimentos que privilegiam a música erudita europeia dos séculos XVIII e XIX. Os traços de colonialidade que ainda perduram no ensino superior de música no Brasil são, dessa forma, resultados do perfil epistemológico hegemonicamente europeu praticado durante os mais de três séculos de colonialidade.

Diante disso, verificamos o epistemicídio de saberes e conhecimentos outros produzidos fora do padrão cultural branco/ocidental. Epistemicídio é um termo forjado por Boaventura de Sousa Santos para denunciar essa destruição dos saberes e conhecimentos produzidos por aqueles considerados, pelo padrão de poder europeu, como inferiores e incapazes.

Para Queiroz (2017, p. 108), o crime de epistemicídio musical cometido com as expressões culturais que historicamente foram expulsas de lugares de destaque na sociedade:

[...] se deu, e ainda hoje se dá, pela associação dessas músicas a outros sistemas de organização sonora e outras formas de expressão cultural, geralmente vinculadas a grupos subalternos ou a práticas que, a partir de valores hegemônicos do hemisfério sul, são consideradas como desprovidas de valor estético, simbólico e social. 
Fora da academia, as Bandas Cabaçais vão sacolejando o cotidiano dos sertões e circulando pelas frestas da colonialidade, assumindo características decoloniais. Vinculam-se ao catolicismo popular e profanam quando saem desse território sagrado. Nas ruas, praças e terreiros dão outros sentidos as suas práticas e insurgem contra os padrões impostos como regra, embora seu repertório tradicional, as formações dos grupos, o jeito de tocar as flautas, dentre outras características, representem fortes marcas da cultura colonial. Nas oficinas de Seu Zé do Pife, as Cabaçais não apenas falam, elas também dançam e cantam, na horizontalidade, dialogando, sem partituras, sem caráter seletivo, sem música erudita ocidental como conhecimento oficial, sem individualismo, sem o objetivo final de tornar o aprendiz em um virtuoso professor. Tudo gira em torno de um instrumento rústico e das possibilidades musicais que ele propicia em nome da vida, da alegria, da brasilidade nordestina.

\section{Considerações finais}

A cada ação afirmativa em favor da música cabaçal mais pessoas chegam, mais a epistemologia cabaçal ganha importância, mais os Mestres sentem que a sua arte pulsa e tem gente para consumi-la. São ações importantíssimas que podem, no nosso entendimento, ampliar as contribuições, sobretudo, se contemplarem não somente as bandas que, de certa forma, já têm luzes sobre elas, como faz, por exemplo, o projeto Tocando Pífanos, produzido no Pernambuco pela Página $21^{12}$, em que se apresentam famosos e não famosos. Para os produtores da Página 21 a preocupação com a salvaguarda, nesse sentido, em se tratando de Bandas Cabaçais, por exemplo, deve ser maior do que o tamanho midiático dos artistas convidados.

As Juvelinas, As Três Marias e o grupo Chinela de Couro são algumas das "estriquinadas do pife" ${ }^{\text {, }}$, frutos do trabalho do Mestre Zé do Pife, em Brasília. Totalmente inserida nessa história poética musical, a professora, musicista e pesquisadora brasiliense Kika Brandão ressalta a importância das mulheres no contexto musical daquela cidade. Um exemplo que pode ser seguido, inclusive, pelas bandas tradicionais, pois o feminino vem mostrando ao patriarcado que a sua vontade de superioridade em relação ao feminino é equivocada e ultrapassada. Quando as mulheres chegam tudo fica mais colorido, mais potente, inclusive a música cabaçal, que toca o cerne da alma de Vitória do Pife, transporta Tauana para as raízes de onde viemos, faz Dani Neri inspirar outras

${ }^{12}$ Disponível em: https://www.facebook.com/pagina21 comunicacao/. Acesso em: 10 jun. 2020.

${ }^{13}$ Expressão utilizada por Kika Brandão para dizer que os músicos são loucos pelo pífano. 
mulheres e tem salvado Kika Brandão durante a pandemia. Essa música vivíssima, como diz Rafaela, têm provocado em suas plateias a vontade de experienciar os grupos tradicionais.

\section{REFERÊNCIAS}

BOFF, L. O despertar da águia: o dia-bólico e o sim-bólico na construção da realidade. 13. ed. Petrópolis, RJ: Vozes, 2000.

BRAGA, E. M. Celebrações da vida: história e memória da Banda Cabaçal Os Inácios. Campina Grande: EDUFCG, 2015.

BRANDÃO, C. R. O que é educação. Coleção Primeiros Passos. 1. ed. São Paulo: Brasiliense, 2013.

LARROSA, J.. Tremores: Escritos sobre experiência. Trad. Cristina Antunes, João Wanderley Geraldi. 1. ed. 5. Reimp. Belo Horizonte: Autêntica, 2020. Coleção Educação: Experiência e Sentido).

PEREIRA, M. V. M. Licenciatura em música e habitus conservatorial: analisando o currículo. Revista da ABEM, Londrina, v. 22, n. 32, p. 90-103, jan./jun. 2014. Disponível em: http:www.abemeducacaomusical.com.br/revistas/revistaABEM/. Acesso em: 29 jul. 2021.

QUEIROZ, L. R. Traços de Colonialidade no Ensino Superior de Música no Brasil: análise a partir de uma trajetória de epistemicídios musicais e exclusões. Revista da ABEM, Londrina, v. 25, n. 39, p. 135 159, jul./dez. 2017.

SANTOS, A. B. Colonização, quilombos: modos e significados. Brasília, 2015.

SANTOS, B. S.; MENESES, M. P. (Org.) Epistemologias do Sul. São Paulo: Cortez, 2010.

SILVA, J. S. A Música Nordestina Brasileira. Revista da Academia Sergipana de Letras, Aracaju, v. 1, n. 39, 2011.

SILVA, V. L. L. "Seu ZÉ, QUAL É A SUA METODOLOGIA?" A aprendizagem musical na Oficina de Pífano da Universidade de Brasília. 2010. Dissertação (Mestrado) Universidade de Brasília, Instituto de Artes, Departamento de Música, Brasília, 2010.

SIMAS, L. A. Almanaque brasilidades: um inventário do Brasil popular. Rio de Janeiro: Bazar do Tempo, 2018.

SIMAS, L. A. O corpo encantado da rua. 5. ed. Rio de Janeiro: Civilização Brasileira, 2019. 


\section{Como referenciar este artigo}

BRAGA, E. M.; LUCINI, M. Práticas educativas e ressignificações dos saberes e fazeres das bandas cabaçais rurais: ações decoloniais no contexto musical urbano/contemporâneo. Revista Ibero-Americana de Estudos em Educação, Araraquara, v. 16, n. 4, p. 2852-2871, out./dez. 2021. e-ISSN: 1982-5587. DOI: https://doi.org/10.21723/riaee.v16i4.15685

Submetido em: 01/08/2021

Revisões requeridas em: 25/09/2021

Aprovado em: 01/10/2021

Publicado em: 21/10/2021 